\title{
CONTROL DE CONSTITUCIONALIDAD COMO GARANTİA JURISDICCIONAL DE LA FUNCIÓN LEGISLATIVA. DESARROLLO NORMATIVO, JURISPRUDENCIAL Y DOCTRINAL, DESDE LA PERSPECTIVA DEL DERECHO CONSTITUCIONAL ESPAÑOL Y COLOMBIANO*
}

Constitutionality control as a guarantee of the legislative function. Normative development, jurisprudential and doctrinal from the perspective of the Spanish and Colombian constitutional law

José Rory Forero Salcedo**

Universidad Libre. Bogotá D.C.

Recepción: 2 de septiembre de 2015. Aceptación: 2 de noviembre de 2015.

DOI:http:/ / dx.doi.org/10.21017/Rev.Repub.2016.v20.a5

\section{RESUMEN}

El trabajo se circunscribe al estudio del control de constitucionalidad como garantía jurisdiccional de la función legislativa, enfatizando en la importancia que reviste para el Estado Constitucional la garantía jurisdiccional de la función legislativa traducida en el control de constitucionalidad, previa aproximación conceptual a la Ley y disposiciones normativas con fuerza de Ley, como objeto del control de constitucionalidad, para determinar el alcance del juicio emitido por la justicia constitucional basado en la inconstitucionalidad formal e inconstitucionalidad material, para constatar partiendo del recurso de inconstitucionalidad, si el control de constitucionalidad es un control político o corresponde a un control eminentemente jurídico, apoyado

* Este artículo es resultado del proyecto de investigación: Vicisitudes del Derecho Disciplinario, desarrollado dentro de la línea de investigación Régimen Disciplinario de los Servidores Estatales del Grupo de Investigaciones Derecho Penal, Derecho Disciplinario y Derechos Humanos, adscrito al Centro de Investigaciones Socio Jurídicas de la Universidad Libre de Bogotá. Grupo reconocido por Colciencias en la categoría A.

** Doctor en Derecho por la Universidad Complutense de Madrid-España. Diplomado en Estudios Avanzados en Derecho Constitucional y Especialista en Derechos Humanos de la misma Universidad. Abogado y especialista en Derecho Público de la Universidad Externado de Colombia. Profesor titular de carrera de la Universidad Libre. Docente investigador del Grupo: Derecho Penal, Derecho Disciplinario y Derechos Humanos, categoría A de Colciencias. Línea de investigación: Régimen Disciplinario de los Servidores Estatales. Correo electrónico: roryf63@yahoo.es 

jurisdiccional de la función legislativa

en la legislación, la doctrina y la jurisprudencia española y colombiana como fuentes del Derecho.

Palabras clave: Estado constitucional, control de constitucionalidad, función legislativa, garantía jurisdiccional, Ley, disposiciones normativas con fuerza de ley, justicia constitucional, inconstitucionalidad formal y material, control político, control jurídico.

\begin{abstract}
The Work is confined to the study of constitutional review as a legal guarantee of the legislative function, emphasizing in the importance implied by the Constitutional State the legislative guarantee translated into control of constitutionality, prior conceptual approach to Law and normative provisions having the force of law, as the subject of control of constitutionality, in order to determine the scope of judgment issued by the Constitutional justice based on formal unconstitutionality and material unconstitutionality to verify starting from the unconstitutionality resource whether the constitutionality control is a political control or corresponds to the eminently legal control supported in Spanish and Colombian legislation, doctrine and jurisprudence as sources of law.
\end{abstract}

Keywords: Constitutional state, constitutionality control, legislative function, judicial guarantee, Law, normative provisions having the force of law, constitutional justice, formal and material unconstitutionality, political control, control Law.

\title{
INTRODUCCIÓN
}

Este artículo, resultado de una noble provocación académica, desarrolla un contenido desde el cual se pretende abordar cuatro objetivos concretos:

1. Enfatizar en la importancia que reviste para el Estado Constitucional la garantía jurisdiccional de la función legislativa traducida en el control de constitucionalidad.

2. Realizar una aproximación conceptual a la Ley y disposiciones normativas con fuerza de ley, como objeto del control de constitucionalidad, para determinar el alcance del juicio emitido por la justicia constitucional basado en la inconstitucionalidad formal e inconstitucionalidad material.

3. Constatar, partiendo del recurso de inconstitucionalidad, si el control de constitucionalidad es un control político o corresponde a un control eminentemente jurídico. 
4. A manera de contextualización realizaré un excursus ordenado conforme a los temas generales planteados.

\section{PROBLEMA A INVESTIGAR}

Como quiera que la investigación se ciñe al estudio del control de constitucionalidad como garantía jurisdiccional de la función legislativa, se busca determinar el alcance del juicio emitido por la justicia constitucional basado en la inconstitucionalidad formal e inconstitucionalidad material, para verificar si el control de constitucionalidad corresponde a un control político o es un control eminentemente jurídico.

\section{METODOLOGÍA}

En una primera parte, se enfatiza en la importancia que reviste para el Estado Constitucional la garantía jurisdiccional de la función legislativa traducida en el control de constitucionalidad.

En un segundo acápite, se hace una aproximación conceptual a la Ley y disposiciones normativas con fuerza de ley, como objeto del control de constitucionalidad, para determinar el alcance del juicio emitido por la justicia constitucional basado en la inconstitucionalidad formal e inconstitucionalidad material.

En un tercer apartado, se constata, partiendo del recurso de inconstitucionalidad, si el control de constitucionalidad es un control político o corresponde a un control eminentemente jurídico.

En este sentido la investigación es descriptiva, explicativa, analítica y crítica.

En consecuencia, realizaré un excursus ordenado conforme a los temas generales señalados en el sumario y a fin de que la investigación guarde coherencia acompañaré en lo pertinente el desarrollo normativo, jurisprudencial y doctrinal de los estatutos que regulan la temática contenidos en la Constitución española de 1978 y la colombiana de 1991, procurando realizar el análisis valorativo, crítico y reflexivo de sus categorías jurídicas.

En aras de una mayor ilustración la relación de textos y autores se irá detallando en el pie de página correspondiente y de manera general al finalizar el mismo. 

jurisdiccional de la función legislativa

\section{RESULTADOS}

\section{Referente histórico}

Se concibe el control jurisdiccional como paradigma del control jurídico y el control de constitucionalidad como una de sus vertientes más importantes. Antes de cualquier consideración es preciso recordar sucintamente el origen de la justicia constitucional.

Para Peralta Martínez la constitucionalidad real y concreta de todo el ordenamiento jurídico de un Estado tiene una evidente dimensión práctica. Y es que en función de esta dimensión, en las naciones de nuestro ámbito geocultural que instituyen la noción de justicia constitucional, se atribuye el control de la mencionada constitucionalidad a un órgano del tipo de un Tribunal de Justicia.

A propósito del origen de esta justicia constitucional, indica el autor, que se encuentra en el mecanismo de la judicial review, instituido en el sistema constitucional norteamericano tras la independencia de ese país. Destaca que esta técnica del judicial review tiene su origen en el common law inglés, en la posición central de este como «Derecho común», «desde la cual el Derecho común puede exigir cuentas a las leyes como normas puramente singulares que son, que penetran en un Derecho común constituido».

Un ejemplo relevante de esta superioridad del common law sobre las leyes del Parlamento se encuentra en la actividad del gran juez Coke «que intentó plasmar en algunas sentencias, sobre todo en la famosa del "Bonham's case" de 1610, un control no ya sobre el alcance y la interpretación de las leyes parlamentarias, sino sobre la validez misma de estas leyes, implicando, por consiguiente, la eventual anulación de las mismas por ser contrarias a los principios fundamentales del sistema, considerados como expresión del Derecho natural».

Señala que esta tesis del juez Coke es la que «van a recoger los constituyentes norteamericanos, declarando en el artículo VI Sección 2 de la Constitución estadoudinense el principio de que la Constitución es el supremo derecho de la tierra y que, por ello mismo, vincula a los jueces por encima de cualquier disposición contraria a las constitucionales».

Es a partir de la sentencia del Tribunal Supremo de 1803 sobre el caso «Marbury v. Madison» cuando la judicial review, como control judicial de la constitucionalidad de las leyes, se convierte en pieza central del sistema jurídico-político norteamericano. En razón de que en la mencionada sentencia se inaplicó una ley federal por entrar en contradicción con la Constitución, es decir, por su inconstitucionalidad. 
De este modo, la Corte Suprema norteamericana se convierte en el defensor y supremo intérprete de la norma fundamental sobre la que se construyó el Estado norteamericano tras obtener su independencia. Así, la Constitución aparece como la ley fundamental, superior a la legislación ordinaria, exigiendo su constitucionalidad, haciendo nula toda ley que sea contraria. ${ }^{1}$

Sobre los sistemas de jurisdicción concentrada y difusa destaca:

«La doctrina norteamericana sobre el control judicial de las leyes no sería contemplada en Europa hasta su recepción por el jurista austriaco Hans Kelsen.

La posición kelseniana se centra en el sistema de "jurisdicción concentrada", frente al sistema de "jurisdicción difusa" propio del constitucionalismo norteamericano; es decir, el control de la constitucionalidad de las leyes se concentra en un solo Tribunal y no en todos los Tribunales como sucede en Norteamérica aunque esta pluralidad de fuentes de decisión sobre la constitucionalidad de las leyes se ordene sobre el principio stare decisis que vincula a todos los Tribunales de la jurisdicción de la Corte Suprema.

Así, para Kelsen el Tribunal Constitucional debe limitarse a resolver la cuestión de la compatibilidad entre una norma ordinaria y la norma suprema, eliminando, anulando aquella en caso de incompatibilidad. Es decir, estaríamos ante un Tribunal muy particular, ya que no es un Tribunal común que enjuicia, que resuelve situaciones concretas.»

Concluye señalando que sobre estos dos sistemas de control judicial de la constitucionalidad de las normas se desarrollará la justicia constitucional en nuestra área histórico-cultural. Aparecerán sistemas afines de justicia constitucional en Alemania e Italia y también en España a partir de la Constitución de $1978^{2}$.

Miremos ahora la situación en el ámbito constitucional colombiano:

1 El carácter superior de la Constitución y la confianza absoluta en sus Jueces es algo que los norteamericanos tenían muy claro cuando se independizaron de Inglaterra. La razón por la cual el postulado de la supremacía de la Constitución tarda en llegar a Europa, radica en que en el siglo XIX en Europa no se cree en el concepto de Constitución, pues lo que prima es el concepto de Ley y en consecuencia la Constitución no es norma superior, amén que la teoría de la soberanía sobre la cual se estructuran los Estados es Nacional y no Popular. De otra parte, existe una desconfianza en los jueces, a quienes se considera simples aplicadores del Derecho sin capacidad de interpretación de normas superiores.

2 Peralta Martínez, Ramón. (1994). La interpretación del ordenamiento jurídico conforme a la norma fundamental del Estado. Servicio de Publicaciones Facultad de Derecho de la Universidad Complutense de Madrid. 
Existe desde principios del siglo XIX en los albores de nuestro constitucionalismo un eficaz sistema de control de constitucionalidad. Basta con observar los textos de los siguientes ordenamientos superiores:

- Constitución Monárquica de 1811, artículo 9:

«Habrá un Senado de censura y protección, compuesto de un Presidente, que lo será el Vicepresidente de la Representación Nacional, y cuatro miembros, para sostener esta Constitución y los derechos del pueblo, a fin de que de oficio o requerido por cualquier ciudadano, reclame cualquiera infracción o usurpación de todos o cada uno de los tres Poderes Ejecutivo, Legislativo y Judicial que sea contra el tenor de la Constitución». ${ }^{3}$

- Constitución Política de la República de Colombia de 1830, artículo 159:

«El Congreso podrá resolver cualesquiera dudas que ocurran sobre la inteligencia de algunos artículos de esta Constitución».4

- Constitución Política del Estado de la Nueva Granada de 1832, artículo 213:

«El Congreso podrá resolver cualesquiera dudas que ocurran sobre la inteligencia de algunos artículos de esta Constitución». ${ }^{5}$

- Constitución Política de la República de la Nueva Granada de 1843, artículo 169: «Las dudas que ocurran sobre la verdadera inteligencia de cualesquiera disposiciones de esta Constitución, pueden ser resueltas por una ley especial y expresa».

- Constitución para la Confederación Granadina de 1858, artículo 50:

«Corresponde a la Corte Suprema suspender la ejecución de los actos de las legislaturas de los Estados, en cuanto sean contrarios a la Constitución o a las leyes de la Confederación; dando cuenta de la suspensión al Senado, para que este decida definitivamente sobre la validez o nulidad de dichos actos».

- Constitución Política de los Estados Unidos de Colombia de 1863, artículo 72:

3 Pombo, Manuel Antonio y Guerra, José Joaquín. (1986). Constituciones de Colombia (Cuarta edición). Estudio preliminar y anexo por Carlos Restrepo Piedrahita. Biblioteca: Banco Popular. Bogotá-Colombia.

4 Restrepo Piedrahita, Carlos. Constituciones Políticas Nacionales de Colombia (Segunda edición). Instituto de Estudios Constitucionales. Universidad Externado de Colombia.

5 Ídem. 
"Corresponde a la Corte Suprema suspender, por unanimidad de votos, a pedimento del Procurador General o de cualquier ciudadano, la ejecución de los actos legislativos de las Asambleas de los Estados, en cuanto sean contrarios a la Constitución o a las leyes de la Unión, dando, en todo caso, cuenta al Senado para que este decida definitivamente sobre la validez o nulidad de dichos actos».

- Constitución Política de la República de Colombia de 1886, artículo 64:

«Son atribuciones de la Corte Suprema: [...] 4. Decidir definitivamente sobre la exequibilidad de actos legislativos que hayan sido objetados por el Gobierno como inconstitucionales».

El acto legislativo número 3 de 1910 representa una de las grandes aportaciones del Derecho constitucional colombiano al Derecho constitucional comparado en materia de control de constitucionalidad por vía de acción con legitimación ciudadana, y basta con observar el contenido de los artículos 40, 41 y 42 de la normativa.

\begin{abstract}
Artículo 40.- En todo caso de incompatibilidad entre la Constitución y la ley se aplicarán preferencialmente las disposiciones constitucionales. Artículo 41.- A la Corte Suprema de Justicia se le confía la guarda de la integridad de la Constitución. En consecuencia, además de las facultades que le confieren esta y las leyes, tendrá la siguiente: Decidir definitivamente sobre la exequibilidad de los Actos Legislativos que hayan sido objetados como inconstitucionales por el Gobierno, o sobre todas las leyes o decretos acusados ante ella por cualquier ciudadano como inconstitucionales, previa audiencia del Procurador General de la Nación. Artículo 42.- La ley establecerá la jurisdicción contencioso-administrativa. (Resaltado fuera del texto).
\end{abstract}

Ahora bien, la Constitución de 1991, retomando esta gran aportación e inspirada en gran medida en la Constitución española de 1978, adoptó un sistema mixto, esto es, una combinación entre el modelo norteamericano (jurisdicción difusa) y el modelo europeo (jurisdicción concentrada) atribuida a la Corte Constitucional ${ }^{6}$.

Se deriva de la Carta Política colombiana la máxima garantía del sistema de control de constitucionalidad principalmente por las siguientes vías:

1. Acción pública de inconstitucionalidad.

2. Excepción de inconstitucionalidad como mecanismo incidental propio de las autoridades judiciales y administrativas.

6 Parece ser la tendencia en los sistemas constitucionales latinoamericanos. 

jurisdiccional de la función legislativa

3. Control automático tratándose de los Decretos legislativos dictados por el Gobierno en estados de excepción y los Decretos-leyes derivados de las facultades extraordinarias conferidas por el Congreso.

4. Acción pública de nulidad a propósito de los demás Decretos que el Gobierno dicte y cuya competencia está atribuida al Consejo de Estado por ser actos administrativos.

5. Objeciones del Gobierno por inconstitucionalidad respecto de proyectos de ley y proyectos de leyes estatutarias tanto por su contenido material como por vicios de procedimiento en su formación.

\section{EL CONTROL DE CONSTITUCIONALIDAD COMO GARANTÍA DEL MODELO CONSTITUCIONAL: ESTADO SOCIAL Y DE- MOCRÁTICO DE DERECHO}

Una de las razones de ser del Estado Constitucional radica en garantizar ${ }^{7}$ los derechos y libertades fundamentales de los ciudadanos. Para tal fin cuenta la organización política con una estructura que descansa en la supremacía Xde la Constitución como postulado básico. En efecto, la norma suprema, al establecer los poderes públicos legislativo, ejecutivo y judicial, determina sus funciones y competencias acorde con una clara separación, en donde los actos y actuaciones de tales poderes se encuentran sometidos a estrictos controles de carácter social, político y jurídico, que permiten restablecer el equilibrio perdido, en un momento dado, por su extralimitación.

En este escenario emerge la función legislativa como una de las atribuciones más importantes del Estado Constitucional. Es la capacidad del poder público para dictar normas jurídicas e imponer conductas obligatorias con capacidad de coacción y cumplimiento, otorgada en principio al poder legislativo (Parlamento o Congreso), pero compartida hoy en el Estado social con el poder ejecutivo (Gobierno) por la quiebra del monopolio parlamentario en su elaboración.

En consecuencia, la actividad legislativa debe obedecer a unas claras reglas de juego en donde sus titulares se encuentran sometidos a la Carta Constitucional que determina su conducta y objetivos.

7 El artículo 16 de la Declaración francesa de Derechos del Hombre y del Ciudadano de 1789 así lo estableció: Toda sociedad en la que no esté asegurada la garantía de los derechos ni determinada la separación de poderes carece de Constitución. 
En el ámbito de esta actividad, el carácter superior de la Constitución como expresión de la voluntad popular soberana se haría nugatorio, si no existiera, de una parte, un Órgano capaz de guardarla e interpretarla en debida forma, y de otra, un instrumento de control como garantía jurisdiccional de la actividad legislativa y naturalmente del Estado Constitucional. ${ }^{8}$ No se puede perder de vista que el fundamento primero y último, superior y común a los poderes públicos radica precisamente en el poder constituyente popular.

Emerge así el control jurisdiccional como paradigma del control jurídico y el control de constitucionalidad como una de sus vertientes más importantes.

Así, el Estado Constitucional se configura como el Estado de Derecho contemporáneo, estructurado en ese principio básico de la supremacía de la Constitución, dado el carácter metajurídico, axiológico y ético de sus normas, del que se deriva a su turno la garantía de derechos como su fin y la separación de poderes como el medio para lograr tal objetivo, acorde con lo estatuido en el artículo 16 de la Declaración de los derechos del hombre y el ciudadano de 1789.

Ahora bien, es natural que si el Estado Constitucional descansa sobre tal postulado, ha de tener un sistema de controles que limite precisamente esos poderes públicos si se extralimitan. En este escenario, emerge el control de constitucionalidad como garantía del Estado Constitucional social y democrático de Derecho para velar por el mantenimiento de dicha supremacía que tiene como fuente primaria la soberanía popular.

Función especialísima, atribuida a los jueces ordinarios (sistema de jurisdicción difusa) o a jueces especializados (sistema de jurisdicción concentrada) y que busca en sede teleológica, la interpretación adecuada de los preceptos constitucionales, buscando dar estabilidad al régimen constitucional pactado, sirviendo como garante legítimo de los derechos fundamentales de los asociados.

\subsection{Teoría constitucional del control}

Señala Aragón Reyes que los conceptos de Constitución y control en el ámbito del Estado Constitucional resultan inescindibles. En efecto, hablar de Constitución tiene sentido cuando se le concibe como un instrumento de limitación y control del poder. ${ }^{9}$

8 En contrapunto, encontramos que Inglaterra no tiene una Constitución escrita ni un Tribunal Constitucional; sin embargo, la Constitución de corte consuetudinario participa de los conceptos de validez y vigencia material.

9 Aragón Reyes, Manuel. (1999). Constitución y control del poder. Universidad Externado de Colombia. 
Destaca el autor:

"En definitiva, el control jurídico (menos "fuerte" que el social y el político) se presenta como el más "regular" (por ser un control normativizado) y, a la postre, el más seguro. La Constitución no podría sobrevivir sin los controles sociales y políticos, sin duda alguna, pero sencillamente, la Constitución no podría "ser" sin el control jurídico que es, por esencia, el control jurisdiccional. Esa es la base en que descansa el Estado Constitucional de Derecho [...] El control jurisdiccional aparece, pues, como algo absolutamente necesario para el concepto y la existencia misma de la Constitución» ${ }^{10}$.

Como se observa, el tema de los controles en el ámbito del Estado Constitucional resulta complejo y conllevaría examinar juiciosamente las diferentes teorías de control planteadas por la doctrina, lo que por limitación espacio-temporal no pretendo hacer, ni corresponde a los objetivos inicialmente pactados.

Sin embargo, sí es necesario asomarnos someramente a los diferentes tipos de control que existen, y para ello una excelente aproximación la encontramos en el texto de Aragón Reyes citado a lo largo de las presentes líneas, en el que de manera cuidadosa desarrolla la temática partiendo de la necesidad de una teoría del control «constitucionalmente adecuada» con fundamento en los siguientes aspectos: El control como elemento inseparable del concepto de Constitución; los problemas conceptuales del control: controles sociales, políticos y jurídicos; el control jurisdiccional como paradigma del control jurídico; características del control político y sus diferencias con el control jurídico y el control social; a modo de ejemplo el control parlamentario como control político y el papel del derecho en las diversas clases de control.

Para nuestro estudio conviene precisar algunas diferencias genéricas entre los controles jurídicos, políticos y sociales que se deducen de los planteamientos realizados por el autor:

Empezando por los agentes del control se infiere que en el control jurídico, lo son los órganos jurisdiccionales como quiera que es un control institucionalizado, por ejemplo el Tribunal Constitucional o la Corte Constitucional; en el control político lo ejercen órganos, autoridades o sujetos de poder cualificados por su condición política, siendo igualmente un control institucionalizado, por ejemplo, el Parlamento o el Pueblo cuando ejercita el control a través del cuerpo electoral; y en el control social son los ciudadanos, grupos de muy diversa índole y los medios de información, siendo este un control no institucionalizado.

10 Ídem. Página 106. 
Si analizamos las diferencias partiendo de los objetos del control, observamos que el control jurídico se efectúa sobre actos o sobre actividades, por ejemplo, cuando el Tribunal o la Corte Constitucional controlan una ley o un Decreto-ley no están controlando al parlamento o al Gobierno, sino simplemente al Derecho. Por su parte, el control político se efectúa sobre órganos u organización, por ejemplo, cuando el Congreso de los Diputados en el caso español está controlando un Decreto-legislativo, está controlando en realidad al Gobierno que lo produce. Por último, la finalidad del control social es una finalidad política y resulta obvio para el autor, pues se trata de controlar al poder, lo que per se no lo convierte en un control político, pues es un control que se efectúa de manera no institucionalizada porque sus agentes no han de someterse para realizarlo a un procedimiento reglado y específico de control. ${ }^{11}$

\subsection{Sistemas de control de constitucionalidad}

En el presente acápite recordaremos sucintamente y a manera de contextualización los diferentes sistemas de control de constitucionalidad planteados por la doctrina, haciendo énfasis en el sistema imperante en el Estado moderno caracterizado por: 1) la supremacía de la Constitución; 2) separación de poderes y 3) poder constituyente como su fuente y base.

Existen dos sistemas básicos: el control previo y el posterior:

A. El control previo ejercido por las mismas asambleas parlamentarias en homenaje a la soberanía del Parlamento, representante directo de la colectividad nacional, excluyendo la intervención judicial ${ }^{12}$ con el argumento de que el magistrado solamente puede estatuir secundum legem.

En Colombia sobre el particular comenta Velásquez Turbay:

«La vigencia del control de constitucionalidad no ha sido admitida con facilidad en el mundo de Occidente. No se ha encontrado un sustento a las funciones de un órgano para que contrarresten las decisiones del órgano de la representación nacional. ¿Con qué autoridad, se pregunta, los jueces constitucionales pueden entender y declarar que los elegidos popularmente han traicionado la Constitución? La verdadera autoridad política, en la democracia, está justamente en los órganos de elección. Esto visto, el control de constitucionalidad resulta un triunfo de la ciencia frente a la democracia: la ciencia jurídica por encima del poder colectivo.

11 Ibídem. Página 110.

12 Constitución política de Colombia. Legis Editores S. A. Página 665. 
Hay entonces un cuestionamiento sobre el funcionamiento del control de constitucionalidad».13

B. El sistema de control posterior adopta dos vertientes: control difuso y control concentrado. ${ }^{14}$

El control posterior difuso se traduce en la facultad otorgada a los jueces y en algunos estados ${ }^{15}$ a las autoridades administrativas (caso colombiano) para el ejercicio de la excepción de inconstitucionalidad ${ }^{16}$ en el curso de un proceso particular o actuación administrativa pero con un efecto limitado. O como sucede en Norteamérica, sistema de jurisdicción difuso por excelencia, donde el control de constitucionalidad de las leyes no se concentra en un solo Tribunal, sino que es propio de todos los Tribunales, cuyas decisiones han de estar articuladas con la jurisprudencia de su Tribunal Supremo.

El control posterior concentrado, es decir, aquel en donde el control de constitucionalidad de las leyes se concentra en un solo Tribunal a su turno comporta dos aspectos:

El primero representado en la acción o recurso de inconstitucionalidad, cuya legitimación puede ser popular, y la tiene todo ciudadano (caso colombiano) o estar atribuida a ciertos órganos o fracciones de órganos (caso español), pero que su decisión recae en jueces especializados, Cortes Constitucionales o Tribunales Constitucionales.

El segundo se materializa en la Magistratura ordinaria, como sucedía en Colombia antes de entrar en vigencia la Constitución de 1991. La decisión recaía

13 Velásquez Turbay, Camilo. Derecho Constitucional. Universidad Externado de Colombia. Segunda Edición.

14 Sin perjuicio del fenómeno que se viene presentando en algunos países en Latinoamérica en cuyo ámbito se está gestando un tercer sistema mixto, pues combina el control difuso y el concentrado, como en el caso colombiano con la Constitución de 1991.

15 Me refiero al Estado colombiano y deriva la facultad del artículo 4 superior que a la letra reza: La Constitución es norma de normas. En todo caso de incompatibilidad entre la Constitución y la Ley u otra norma jurídica, se aplicarán las disposiciones constitucionales.

Es deber de los nacionales y de los extranjeros en Colombia acatar la Constitución y las leyes, y respetar y obedecer a las autoridades.

16 El Consejo de Estado en Colombia, Sala Plena, en sentencia de abril 1/97 sobre el tema indicó: Puede verse con facilidad que el sistema de control constitucional por vía de excepción se amplió con el nuevo precepto (artículo 4 de la Constitución colombiana) y, por lo tanto, un acto administrativo, que desde luego es norma jurídica, puede ser inaplicado si viola el estatuto constitucional, aunque haya creado una situación jurídica de carácter particular y concreto o reconocido un derecho de igual categoría. 
en la Corte Suprema de Justicia como máxima instancia de la jurisdicción ordinaria, pues no existía la jurisdicción constitucional que viene a concebirse con el Estatuto constitucional de 1991.

A propósito de la elaboración de sistemas de control de constitucionalidad en Europa comenta García De Enterría:

«La recepción en Europa de la doctrina americana del control judicial de las leyes va a ser, por tanto, muy tardia, concretamente en la primera posguerra de este siglo (siglo XX), en 1919-1920, y va a ser la obra personal de un jurista genial, Hans Kelsen. Estructuralmente el sistema Kelseniano introduce un cambio básico, que es concretar la jurisdicción de control de constitucionalidad de las leyes en un solo Tribunal y no, como en el sistema americano genuino, en todos los Tribunales, sibien esta pluralidad de fuentes de decisión sobre la constitucionalidad de las leyes se ordena sobre el principio stare decisis, que vincula todos los Tribunales a la jurisprudencia de la Corte Suprema. La fórmula Kelseniana consagra así lo que se ha llamado un sistema de "jurisdicción concentrada" frente al sistema de "jurisdicción difusa", propio del constitucionalismo americano ${ }^{17}$ ».

\section{LA NORMA CON FUERZA DE LEY COMO OBJETO DEL CON- TROL DE CONSTITUCIONALIDAD: INCONSTITUCIO- NALIDAD FORMAL Y MATERIAL}

La Ley y las disposiciones normativas con fuerza de Ley representan el objeto del control de constitucionalidad como garantía jurisdiccional no solamente de la función legislativa desarrollada por los poderes públicos legislativo y ejecutivo, sino también de la Constitución y del Estado Constitucional.

El Tribunal Constitucional español señala que el objeto de los procesos de declaración de inconstitucionalidad (incluida la cuestión de inconstitucionalidad) no es la norma, sino la Ley, el texto legal o vehículo formal como «signo sensible» a través del cual se manifiesta el mandato normativo ${ }^{18}$.

En el presente acápite nos aproximaremos al objeto del control bajo estudio, es decir, a las leyes y disposiciones normativas con fuerza de ley, tema que se encuentra en conexión con el de la inconstitucionalidad formal ${ }^{19}$, esto es, vicios

17 García De Enterría, Eduardo. La Constitución como norma y el Tribunal Constitucional. Madrid-España: Editorial Cívitas S. A.

18 S. 332/1993, de 12-11.

19 En este sentido el artículo 28 de la Ley Orgánica 2/79: 

jurisdiccional de la función legislativa

de procedimiento en el proceso de elaboración de la ley; e inconstitucionalidad material ${ }^{20}$, o sea, la incompatibilidad manifiesta entre una norma con fuerza de ley y la Constitución, por lo que se hace menester pasar revista a tres aspectos fundamentales: quién hace la ley, cómo se hace la ley y tipos de normas objeto de control.

\subsection{Quién hace la norma con fuerza de ley}

En el siglo XIX tal atribución recaía exclusivamente en los Parlamentos hasta el advenimiento del Estado social de Derecho en donde el poder ejecutivo juega un papel determinante en la producción de disposiciones normativas con fuerza de ley, configurándose la primera quiebra del monopolio parlamentario de la función legislativa, traducida en el poder legislativo del ejecutivo. Es el binomio: Parlamento y Gobierno en la elaboración de la norma.

Posteriormente llegaría la quiebra del monopolio estatal de la función legislativa, representada en algunos estados en la normativa comunitaria (Unión Europea) y la legislación autonómica en el Estado español.

\subsubsection{El poder legislativo del Ejecutivo}

En cuanto a la primera quiebra, se observa cómo en el ámbito del Estado liberal del siglo XIX la función legislativa recaía de manera exclusiva en el Parlamento o en el Congreso en los estados que adoptaron la forma republicana, en tanto constituían sus órganos representativos caracterizados por el pluralismo como esencia de la democracia.

Con la implantación del modelo social de Estado en el siglo XX, en un nuevo escenario y con nuevas reglas de juego, viene a ser compartida la función legislativa con el poder ejecutivo, como única manera de que este responda al

«2. Así mismo el Tribunal podrá declarar inconstitucionales por infracción del artículo 81 de la Constitución los preceptos de un decreto-ley, decreto legislativo, ley que no haya sido aprobada con el carácter de orgánica o norma legislativa de una Comunidad Autónoma en el caso de que dichas disposiciones hubieran regulado materias reservadas a ley orgánica o impliquen modificación o derogación de una ley aprobada con tal carácter cualquiera que sea su contenido.»

20 En este sentido igualmente el artículo 28 de la Ley Orgánica 2/79:

«1. Para apreciar la conformidad o disconformidad con la Constitución de una ley, disposición o acto con fuerza de ley del Estado o de las Comunidades Autónomas, el Tribunal considerará, además de los preceptos constitucionales, las leyes que, dentro del marco constitucional, se hubieran dictado para delimitar las competencias del Estado y las diferentes Comunidades Autónomas o para regular o armonizar el ejercicio de las competencias de estas.» 
incremento de la actividad asistencial, prestacional y económica que cada día le demandan; lo que determina no solamente el espectacular aumento del gasto público o que se modifique sustancialmente la estructura de su administración pública, sino que cambien radicalmente las relaciones entre el Parlamento y el Gobierno, en tanto este último tiene la posibilidad de dictar normas con rango de ley: en España, Decretos legislativos (legislación delegada) o Decretos-leyes (legislación de emergencia), ampliándose de esta manera el radio de acción del control de constitucionalidad. En Colombia, Decretos Ley y Decretos legislativos.

\subsubsection{La normativa comunitaria y la legislación autonómica}

En cuanto a la segunda quiebra, esta vez del monopolio estatal en la función legislativa por la normativa comunitaria y la legislación autonómica o legislación territorial, también resulta evidente la ampliación del radio de acción del control de constitucionalidad.

En el primer escenario se configuran organismos supranacionales en que los estados renuncian a ejercitar ciertas competencias atribuidas a tales organismos y en donde el control resulta complejo.

En el segundo caso, por el fenómeno de la descentralización política se da la posibilidad de que exista, como en el caso español, un ordenamiento y una legislación autonómica que obedece sin duda a un reparto vertical de poder. El control de constitucionalidad corresponde de manera exclusiva al Tribunal Constitucional.

\subsection{Cómo se hace la norma con fuerza de ley}

\subsubsection{Procedimiento legislativo}

Se define como un único concepto integrado por una pluralidad de actos parlamentarios o extraparlamentarios ordenados hacia un fin común traducido en la creación de la ley dentro de un todo unitario que comporta varias fases: iniciativa, deliberación, resolución y sanción ${ }^{21}$.

Como se observa, el proceso de elaboración de la ley en sede parlamentaria constituye el primer elemento de garantía de la ley misma y supone la confección perfecta en cuanto a su forma y contenido, como quiera que el control de constitucionalidad se puede plantear posteriormente no solamente por la in-

21 Parece ser la tendencia de los estados constitucionales de nuestro entorno. 

jurisdiccional de la función legislativa

compatibilidad entre la Constitución y el contenido de la ley (inconstitucionalidad material), sino también por vicios en el procedimiento legislativo, es decir, ausencia de requisitos elementales como la participación de minorías y la publicidad del procedimiento (inconstitucionalidad formal).

En cuanto a la forma de elaboración de la ley existen unos requisitos complejos y extensos que representan su razón de ser y que podemos concretar, de un lado, en la participación de las minorías, las que deben hacerlo en todas las fases del procedimiento; de otro, la publicidad de los procedimientos, en tanto la comunidad debe saber lo que hacen sus representantes, como una manera de que el pueblo ejerza el control sobre el Parlamento. Es claro que en ausencia de estos requisitos entra como único remedio para reestablecer el equilibrio perdido, el control de constitucionalidad como paradigma de la garantía jurisdiccional de la función legislativa.

\subsubsection{Procedimiento gubernamental}

En contrapunto, el procedimiento gubernamental resulta simple frente al anterior, porque a pesar de regular función legislativa y dictar normas con rango de ley, no se dan los requisitos vistos: la participación de minorías y la publicidad, lo que obedece a la naturaleza misma de este procedimiento. ${ }^{22}$

Un estudio juicioso del control de constitucionalidad de la función legislativa que corresponde al Gobierno, atribuido igualmente al Tribunal Constitucional en España y a la Corte Constitucional en Colombia, implicaría auscultar en el ordenamiento español los siguientes temas:

1. La legislación delegada: los decretos legislativos.

1.1. Leyes de base y textos refundidos.

1.2. El control parlamentario sobre los decretos legislativos.

2. La legislación de urgencia: los decretos leyes.

2.1. El control parlamentario de los decretos leyes: su convalidación.

2.2. La tramitación parlamentaria de los decretos leyes como proyectos de ley.

Y en el ordenamiento colombiano:

22 Los decretos legislativos tienen una garantía parlamentaria en tanto que en los decretos-leyes no hay garantía. 
1. Los Decretos-leyes expedidos por el presidente de la República, previas facultades extraordinarias otorgadas por el Congreso que no podrán superar los seis meses, y siempre que la necesidad lo exija o la conveniencia pública lo aconseje. Tales facultades deberán ser solicitadas expresamente por el Gobierno y su aprobación requiere la mayoría absoluta de los miembros de una y otra Cámara. El Congreso puede en todo tiempo y por iniciativa propia modificar los decretos leyes dictados por el Gobierno en uso de estas facultades extraordinarias, las que no se pueden conferir para expedir códigos, leyes estatutarias, orgánicas ni para decretar impuestos.

2. Los decretos legislativos dictados por el presidente de la República con la firma de todos los ministros en estados de excepción (estado de guerra exterior, estado de conmoción interior, estado de emergencia económica, social y ecológica), los cuales deben ser enviados por el Gobierno a la Corte Constitucional al día siguiente de su expedición para que aquella decida sobre su constitucionalidad. Si el Gobierno no cumple con el deber de enviarlos, la Corte Constitucional aprehenderá de oficio y en forma inmediata su conocimiento.

3. Los actos (decretos, ordenanzas y acuerdos) que dicten las instituciones (Asambleas, Gobernaciones, Concejos y Alcaldías) que conforman las entidades territoriales (Departamentos, Distritos, Municipios y Territorios Indígenas) no tienen la virtud de ser actos de naturaleza legislativa, sino que son actos administrativos cuyo control de constitucionalidad está atribuido por expreso mandato del artículo 237 numeral 2 superior, a la jurisdicción de lo contencioso administrativo, vale decir, al Consejo de Estado y a los Tribunales de lo Contencioso Administrativo que tienen su sede en los Departamentos, siendo a esta jurisdicción a la que corresponde determinar la constitucionalidad de estas normas infralegales, pero no por vía de la acción de inconstitucionalidad sino a través de la acción igualmente pública de nulidad. ${ }^{23}$

\subsection{Tipos de normas objeto del control}

El tipo de normas objeto del control de constitucionalidad se deriva de lo señalado en el acápite inmediatamente anterior. En consecuencia:

En el ordenamiento jurídico español encontramos en primer término las leyes orgánicas y ordinarias, en tanto componente moral y ético del Parlamento,

23 En el ordenamiento español el control de los decretos ordinarios, reglamentos o simplemente actos administrativos se verifica por un sistema mixto: difuso, en cuanto cualquier Juez puede hacerlo en ejercicio del control de legalidad; y concentrado, en cuanto llegue a conocimiento del Tribunal Supremo, Sala de lo Contencioso administrativo, pero como control de legalidad y no de constitucionalidad, a diferencia de lo que sucede en el ordenamiento colombiano que es como control de constitucionalidad. 

jurisdiccional de la función legislativa

aprobadas por la mayoría pero con respeto de las minorías. En segundo término las normas producto de la legislación delegada, los decretos legislativos, las leyes de base y textos refundidos; y en la legislación de urgencia: los decretos leyes.

En el ordenamiento jurídico colombiano, las normas objeto de control son variadas: actos reformatorios de la Constitución, convocatoria a un referendo o a una Asamblea Constituyente para reformar la Constitución; referendos sobre leyes, consultas populares y plebiscitos del orden nacional, leyes en general; decretos con fuerza de ley dictados por el Gobierno, decretos legislativos de estados de excepción; proyectos de ley que hayan sido objetados por el Gobierno como inconstitucionales y proyectos de leyes estatutarias; tratados internacionales y de las leyes que los aprueben.

\section{EL CONTROL DE CONSTITUCIONALIDAD: ¿CONTROL POLÍTICO O CONTROL JURÍDICO?}

Debate álgido en la doctrina ha suscitado este tema. Algún sector considera el control de constitucionalidad como paradigma del control jurídico y otro lo entiende como un control político. En principio, podríamos pensar que el paradigma del control jurídico es el control de constitucionalidad, en tanto que el del control político lo sería el control parlamentario.

Veamos la cuestión con calma:

Señala Pérez Tremps al respecto:

«La incorporación al esquema institucional español de una jurisdicción constitucional se ha hecho siguiendo, al menos en su aspecto organizativo, el modelo Kelseniano de un Tribunal especial. La naturaleza de la jurisdicción constitucional, así configurada, ha sido cuestionada tratando de negarse por ciertos sectores doctrinales su carácter jurisdiccional [...] La discusión sobre la naturaleza jurisdiccional o no de la justicia constitucional arranca desde los mismos orígenes de la construcción de Hans Kelsen [...] Estos argumentos son: la calificación que el mismo Kelsen diera de "legislador negativo" a la justicia constitucional e, íntimamente ligado con ello, la naturaleza política del juicio de constitucionalidad».

El autor analiza el fenómeno desde dos puntos de vista:

1. La superación del sentido objetivo de la justicia constitucional: Comenta que Kelsen no se muestra muy seguro de si el Tribunal Constitucional por él creado es un 
órgano jurisdiccional o no, aunque se inclina por una respuesta en sentido positivo. Al tratar de explicar su función dice que esta es verdaderamente jurisdiccional; y cuando se refiere a un legislador negativo, Kelsen no lo hace tanto pensando en la naturaleza del órgano como en el efecto de su función política, que representa la «cruz» de la moneda: El Parlamento aprueba leyes que un Tribunal puede anular. La función es jurisdiccional en tanto es un Tribunal quien la cumple, actuando con un margen de discrecionalidad mucho más reducido que el del Parlamento.

2. Lo político y lo jurisdiccional en la justicia constitucional: Es la segunda objeción que se hace a la justicia constitucional y radica según el autor en considerar que su función no es jurisdiccional sino que participa del carácter político que su actividad tiene.

Indica que el exponente más claro de esta postura es Carl Schmitt ${ }^{24}$ en su obra La defensa de la Constitución. Agrega que la significación política de los conflictos de naturaleza constitucional resulta obvia; pero que no solamente en el campo constitucional se acusa esta politicidad sino en el de todo el Derecho público, e incluso, en amplios ámbitos del Derecho privado en tanto pueda mantenerse esa dicotomía. Enfatiza:

«Pero la afirmación de que todo juicio de constitucionalidad es un juicio político no basta para privarle de la naturaleza jurisdiccional, ya que lo "político" y lo "jurisdiccional" no son categorías excluyentes entre sí [...] el hecho de que los conflictos constitucionales, entendidos en sentido amplio, tengan una gran trascendencia política no significa que su resolución no pueda sujetarse a criterios de Derecho y a formas jurisdiccionales; ese es el sentido de la justicia constitucional, la reducción del conflicto a unos cauces jurídicos, sin que ello suponga el ignorar su naturaleza política. La aportación de la justicia constitucional es, pues, de carácter técnico y atañe a los medios de superación del conflicto: resolución por un Tribunal -órgano independiente-, sujeto solo al Derecho [...] Menos sentido tiene aún el tratar de privar de carácter jurisdiccional a los Tribunales constitucionales atendiendo a la participación de órganos políticos en la designación de sus miembros [...] Nadie, por ejemplo, duda de que el Tribunal Supremo americano sea un auténtico Tribunal pese a que sus miembros sean nombrados por el Presidente "con el consejo y consentimiento del Senado" (Artículo 2.2. de la Constitución de los Estados Unidos) [...] Lo que hace que un órgano tenga carácter jurisdiccional son las técnicas de actuación y su independencia, cuyas garantías proceden, más que de la forma de elección de sus miembros, de las condiciones exigidas para ser elegible $y$, sobre todo, de su falta de dependencia respecto de otros poderes, incluidos aquellos que los nombraron

24 En este sentido resulta interesante el Prólogo a la segunda edición de la editorial Tecnos del profesor D. Pedro De Vega García. 
[...] En consecuencia, pues, la consideración del carácter jurisdiccional, en lo funcional y en lo orgánico, de la justicia constitucional y, por tanto, del Tribunal Constitucional, parece suficientemente probada».

Resulta conveniente traer a colación igualmente las diferencias planteadas por el profesor Aragón Reyes ${ }^{25}$ en la medida que ilustra una de las tendencias.

\subsection{El control de constitucionalidad como control jurídico}

Partiendo de cuatro parámetros de diferenciación, esto es, el carácter objetivo o subjetivo, el juicio o la valoración del objeto sometido a control, su carácter necesario o voluntario y el carácter de los órganos que ejercen el control, comenta:

«La primera diferencia consiste en el carácter "objetivado" del control jurídico, frente al carácter "subjetivo" del control político. Ese carácter objetivado significa que el parámetro o canon de control es un conjunto normativo, preexistente y no disponible para el órgano que ejerce el control jurídico. En cambio, el carácter "subjetivo" del control político significa todo lo contrario: que no existe canon fijo y predeterminado de valoración, ya que esta descansa en la libre apreciación realizada por el órgano controlante, es decir, que el parámetro es de composición eventual y plenamente disponible.

La segunda diferencia, consecuencia de la anterior, es que el juicio o la valoración del objeto sometido a control está basado, en el primer caso, en razones jurídicas (sometidas a reglas de verificación) y, en el segundo, en razones políticas (de oportunidad).

La tercera diferencia consiste en el carácter "necesario" del control jurídico frente al "voluntario" del control político. Necesario el primero no solo en cuanto que el órgano controlante ha de ejercer el control cuando para ello es solicitado sino también en que si el resultado del control es negativo para el objeto controlado el órgano que ejerce el control ha de emitir, necesariamente, la correspondiente sanción, es decir, la consecuencia jurídica de la constatación (anulación o inaplicación del acto o la norma controlada.) Mientras que el carácter voluntario del control político significa que el órgano o el sujeto controlante es libre para ejercer o no el control y que, de ejercerse, el resultado negativo de la valoración no implica, necesariamente, la emisión de una sanción.

25 Aragón Reyes, Manuel. Constitución y control del poder. Introducción a una teoría constitucional del control. (1999). Editorial Universidad Externado de Colombia. 
La última diferencia relevante que queda por destacar es la que se refiere al carácter de los órganos que ejercen uno u otro tipo de control. El control jurídico es realizado por órganos imparciales, independientes, dotados de especial conocimiento técnico para entender de cuestiones de Derecho: en esencia, los órganos judiciales; mientras que el control político está a cargo precisamente de sujetos u órganos políticos» (Resalto).

Indica finalmente:

«No puede decirse lo mismo, en cambio, respecto de los "objetos" del control, ya que las decisiones "políticas" pueden ser, muchas veces, sometidas a control jurídico y, sobre todo, las normas jurídicas pueden ser sometidas, en ciertos casos, al control político (por ejemplo, los decretos-leyes en los que la intervención parlamentaria tiene, aparte de otras características, el significado de un control).»

\subsection{El control de constitucionalidad como control político}

\section{Comenta en España De Vega García:}

"Como es sabido, cuando Schmitt publica "La defensa de la Constitución" - en la que subyace como gran interrogante: ¿Quién debe ser el guardián de la Constitución?- la realidad política constitucional liberal presenta ya una solución práctica al problema, con la creación de la Constitución austríaca de 1920, por mediación del gran jurista Hans Kelsen, del primer Tribunal Constitucional. Será, pues, contra esa solución Kelseniana, como racionalización jurídica máxima del aparato institucional liberal, contra la que reaccione Carl Schmitt. Su tesis es de sobra conocida: ningún Tribunal de justicia puede ser el guardián de la Constitución. En su lugar, sostendrá que es el Jefe del Estado, esto es, el Presidente del Reich, quien únicamente puede ostentar ese noble y honroso título» 26

Velásquez Turbay ${ }^{27}$ al respecto y partiendo de que el control de constitucionalidad es un mecanismo orientado a garantizar e imponer la superioridad de la norma constitucional, manifiesta:

26 De Vega García, Pedro. Prólogo a la segunda edición de La defensa de la Constitución. Ed. Tecnos.

27 Velásquez Turbay relaciona el control de constitucionalidad con el tema de la libertad como justificación última del constitucionalismo y afirma: «En la Constitución, la libertad se encuentra genéricamente desarrollada, apenas se hacen enunciados a manera de principios, cuyos alcances posteriores son fijados por la ley ordinaria. Para que esto no fuera así, tendríamos que incluir, como parte de la Constitución, todo lo que se denomina el régimen de la libertad; habría que incluir todo el código penal, que limita la libertad; habría que incluir igualmente toda la legislación de tipo policivo; además, toda la legislación en materia de asociación y de reunión, el 

jurisdiccional de la función legislativa

«Sobre la naturaleza del control de constitucionalidad, realmente no hay acuerdo entre los autores. Para algunos es un control de carácter político, para otros es un control de carácter jurídico, un control de legalidad. La verdad es que los tribunales e instancias encargados del control de constitucionalidad se comportan con un doble carácter, jurídico y político.

Si la Corte Suprema de Justicia decidió actuar de acuerdo con el orden jurídico y frente al acto que convocó a una asamblea constituyente (decreto de estado de excepción 1926/90) debió, necesariamente, declarar su inconstitucionalidad. Sin embargo, la Corte, en ejercicio del control de constitucionalidad, consideró políticamente necesaria la convocatoria de una Asamblea constituyente (consideración fundada en el voto de dos de sus miembros), como un mecanismo suficiente, que permitió medir la voluntad colectiva, ejercer un control político de la Constitución vigente».

Se refiere al autor al hecho sui generis acontecido en Colombia y conocido como el movimiento de la "séptima papeleta», que dio lugar a la conformación de una Asamblea Nacional Constituyente encargada de redactar la actual Constitución de 1991.

Por considerarlo de vital importancia para el tema estudiado, pues configura un posible ejemplo del control de constitucionalidad como control político, es menester conocer sus antecedentes.

En efecto, durante la fase final del trámite de la reforma constitucional promovida por el gobierno del presidente Virgilio Barco se propuso, en diciembre de 1989, convocar a un «Referendo extraordinario por la paz y la democracia» que debería realizarse el 21 de enero de 1990 para consolidar los acuerdos de paz con el movimiento insurgente del M-19. La presión violenta del narcotráfico

derecho a huelga, los sindicatos, sociedades, fundaciones, etc. En una palabra, todo el ordenamiento legal. Una Constitución de este modo extensa sería altamente peligrosa, tanto por su extensión como por su dificultad para reformarla. Por su extensión, en la medida que el principio de la superioridad, frente al texto ordinario (de allí la expresión ley ordinaria), se vería, con demasiada frecuencia, violado; la intangibilidad de la Constitución, según aquella hipótesis, perdería su respetabilidad, su carácter extraordinario. Aparece así la necesidad de que algunos órganos del Estado expidan las leyes para los hechos ordinarios. En ese ejercicio de desarrollo constitucional por la ley, la interpretación de la libertad consagrada en la Constitución resulta un asunto político, porque tiene el carácter de una interpretación sobre sus alcances, su precisión y cuyos contenidos obedecen a las opiniones dominantes en el Congreso y en el Ejecutivo. Allí hay un punto móvil: ¿hasta dónde se puede limitar la libertad para garantizar en ese criterio variable, en esa zona imprecisa? ¿Cómo puede sobrevenir la intervención de un control de constitucionalidad, que no entre también en esa zona amplia de interpretación?» 
para que con ocasión de esta consulta el pueblo se pronunciara también sobre la extradición, obligó al gobierno a hundir la totalidad del proyecto.

A comienzos de 1990 estudiantes de varias universidades del país impulsamos la inclusión de una «séptima papeleta» en los comicios del 11 de marzo de ese mismo año, para apoyar la convocatoria de una asamblea constituyente, a pesar de que este mecanismo de reforma constitucional no estaba autorizado en la Constitución de 1886, vigente para la época, y contrariaba expresa prohibición constitucional (artículo 13 del plebiscito de 1957). El respaldo a esta iniciativa por algo más de dos millones de votos que informalmente fueron escrutados, creó una situación de facto que el gobierno implementó mediante el Decreto 927 de 1990, por el cual se facultó a la organización electoral para contabilizar los votos que se depositaran en las elecciones presidenciales del 27 de mayo de 1990 para expresar apoyo o rechazo a la posibilidad de convocar una asamblea encargada de reformar la Constitución.

Posesionado de la Presidencia de la República, César Gaviria expidió, en ejercicio de las facultades de estado de sitio, el Decreto 1926 de 1990, por el cual se fijaba el temario sobre el cual debía versar la reforma de la Constitución y se convocó a los colombianos para que el 9 de diciembre de 1990 eligieran a los miembros de la Asamblea. Al revisar la constitucionalidad del decreto, la Corte Suprema de Justicia, en sentencia de octubre 9 de 1990, dispuso que la Asamblea Constituyente, como órgano habilitado para ejercer el poder constituyente, no tenía límites en sus competencias y declaró en ese sentido la inexequibilidad del decreto en cuanto que, al fijarle temario a la Asamblea, le restringía sus atribuciones; en lo demás se anunció su exequibilidad. De esta manera la Asamblea quedó facultada para reformar íntegramente la Carta Política, como en efecto lo hizo el año siguiente, cuando expidió la Constitución de 1991 que hoy rige.

Finalmente destaca Velásquez Turbay:

«En resumen, tenemos que, al tiempo de los controles propiamente jurídicos, existen controles políticos de constitucionalidad. Los mecanismos de control constitucional plantean una problemática sobre su naturaleza: se trata de una naturaleza jurídica o de una naturaleza política. Ante la necesidad de que el ordenamiento legal se halle en correspondencia con el ordenamiento constitucional viene a presentar un problema solo resuelto de manera imperfecta; la primera solución consiste, históricamente, en reconocer a los organismos de control una capacidad para revisar las leyes con respecto a la Constitución por "vicios de forma", es decir, por vicios en su procedimiento de elaboración, mas estaba vedado a los organismos encargados de la guarda de la Constitución el conocer sobre el contenido mismo de la ley, en razón de que este contenido ha 

jurisdiccional de la función legislativa

sido interpretado de manera acorde con la Constitución por los poderes democráticos del Estado. Hemos visto cómo la legislación en el Estado moderno es fundamentalmente el resultado de un acuerdo entre el poder ejecutivo y los órganos de representación nacional, es decir, los congresos o parlamentos. Como estos órganos representan la voluntad política de la sociedad, renovada de tiempo en tiempo, en los sucesivos procesos electorales, no es lógico que ese congreso y ese gobierno, cuando creen interpretar la Constitución y desarrollarla, puedan encontrar un límite en otro órgano del Estado, que no tiene la misma autoridad política. Por eso, en cuanto a los contenidos, la primera aproximación al control de constitucionalidad fue la de negar ese control de los contenidos materiales de la ley. Pero surge allí un problema fundamental: ¿cómo asegura el Estado que la mayoría de las normas de la Constitución, que no son normas de procedimiento, se encuentren a salvo, no sean contrariadas por la legislación ordinaria? En esencia, este asunto involucra el problema de la libertad; la libertad es la justificación última del constitucionalismo [...] De aquí, y por la necesidad de garantizar la libertad consagrada en la Constitución, el control de constitucionalidad ha venido a parecer como un control político».

En suma, podemos afirmar (y es la tendencia del control de la Constitución en nuestra época) que, además de un control jurídico, se ha constituido en un control político.

Por tanto, no se puede descartar tajantemente la tesis que identifica la naturaleza política del control de constitucionalidad. En este sentido, me identifico con la teoría según la cual los Tribunales e instancias encargados del control de constitucionalidad se comportan con el doble carácter: jurídico y político.

\section{CONCLUSIONES}

1. Con los elementos de juicio aportados, constatamos la importancia que reviste para el Estado Constitucional la garantía jurisdiccional de la función legislativa traducida en el control de constitucionalidad. En efecto, la norma objeto del control de constitucionalidad tiene como elemento de garantía el principio de constitucionalidad, que supone el reconocimiento de la Constitución como norma superior objetiva, que define un régimen de libertades, un control del poder y un reparto de competencias entre los diferentes poderes dentro del Estado.

Se colige en consecuencia:

A. La Ley y disposiciones normativas con fuerza de ley representan el objeto del control de constitucionalidad como garantía jurisdiccional no solamente de la función legislativa desarrollada por los poderes públicos legislativo 
y ejecutivo, sino también de la Constitución y en consecuencia del Estado Constitucional.

B. Dentro del proceso de elaboración de la norma y en su culminación con la norma misma se pueden contravenir valores constitucionales superiores desconociendo intereses generales de los ciudadanos y de las minorías políticas.

C. Siendo la norma elemento clave dentro del Estado Constitucional, social y democrático de Derecho, resulta necesario su control jurisdiccional; concepto que, tras una larga evolución histórica, se inicia en Norteamérica en el siglo XIX y concluye en Europa en el siglo XX con la justicia constitucional, acorde con los sistemas de jurisdicción concentrada y difusa.

2. La aproximación conceptual a la Ley y a la disposición normativa con fuerza de ley, como objeto de los procesos de constitucionalidad, nos permite determinar el alcance del juicio emitido por la justicia constitucional basado en la inconstitucionalidad formal e inconstitucionalidad material. En suma:

A. El proceso de elaboración de la ley en sede parlamentaria constituye el primer elemento de garantía de la ley misma y supone la confección perfecta en cuanto a su forma y contenido, como quiera que el control de constitucionalidad se puede plantear posteriormente por vicios en el procedimiento tales como ausencia de requisitos elementales, verbi gracia, la participación de minorías y la publicidad del procedimiento (inconstitucionalidad formal).

B. Representando la supremacía de la Constitución un postulado básico del Estado Constitucional, es claro que el control de constitucionalidad se puede plantear por la incompatibilidad entre la Constitución y el contenido de la ley (inconstitucionalidad material).

C. En consecuencia, el procedimiento legislativo ajustado en un todo a la Constitución, respetuoso de la participación de las minorías y del principio de publicidad, se consolida en la primera garantía del Estado Constitucional.

3. Apoyado en la Legislación, la Doctrina y la Jurisprudencia española y colombiana como fuentes del Derecho, se puede constatar la naturaleza especial del control de constitucionalidad, en tanto los Tribunales e instancias encargados del mismo se comportan con un carácter jurídico y político.

Jurídico, por el carácter objetivado; juicio o valoración del objeto sometido a control, basado en razones jurídicas sometidas a reglas de verificación; carácter necesario; y control realizado por órganos imparciales, independientes, dotados de especial conocimiento técnico para entender de cuestiones de Derecho. 
Político, porque en el ejercicio del desarrollo constitucional por la ley ordinaria, la interpretación de la libertad consagrada en la Constitución resulta un asunto político, porque tiene el carácter de una interpretación sobre sus alcances, su precisión y cuyos contenidos obedecen a las opiniones dominantes en el Congreso y en el Ejecutivo.

4. El control de constitucionalidad por órganos de naturaleza jurídica se expresa a través de dos mecanismos: un control por vía de acción (recurso o acción de inconstitucionalidad) y un control por vía de excepción (cuestión de constitucionalidad o excepción de inconstitucionalidad). En cuanto al primero existen diferencias sustanciales en la forma como opera la figura en el ordenamiento jurídico español y colombiano, principalmente en aspectos como: titularidad o legitimación, normas objeto de revisión, plazos, procedimiento, etc.

5. El sistema de control de constitucionalidad posterior adopta dos vertientes: control difuso y control concentrado:

El control posterior concentrado, es decir, aquel en donde el control de constitucionalidad de las leyes se concentra en un solo Tribunal, es el que se adopta tanto en España como en Colombia, con las matizaciones vistas.

El control posterior difuso se traduce en la facultad otorgada a los jueces y en algunos estados a las autoridades administrativas (caso colombiano) para el ejercicio de la excepción de inconstitucionalidad en el curso de un proceso particular o actuación administrativa pero con un efecto limitado. O como sucede en Norteamérica, sistema de jurisdicción difusa por excelencia, donde el control de constitucionalidad de las leyes no se concentra en un solo Tribunal, sino que es propio de todos los Tribunales, cuyas decisiones han de estar articuladas con la jurisprudencia de su Tribunal Supremo; considerado como la máxima representación de la ideología americana, de su identidad nacional, hasta el punto de tejerse sobre esta institución toda una mitología religiosa. En palabras de Miller:

«La Constitución como texto inspirado por Dios, los fundadores como los santos, los Jueces del Tribunal Supremo como los sumos sacerdotes que cuidan del culto al texto sagrado en el "Marbel Palace", en el Palacio de Mármol donde tiene su sede y que extraen de ese texto poco menos que la infalibilidad».28

28 A. S. Miller. (1978). The Supreme Court. Myth and reality, citado por García De Enterría, en La Constitución como norma y el Tribunal Constitucional. Página 127. 


\section{REFERENCIAS}

ALEXY, Robert (2003). Derechos Fundamentales y Estado Constitucional Democrático. En: CARBONELL, Miguel -Compilador-. Neoconstitucionalismo(s). Editorial Trotta.

ARAGÓN REYES, Manuel. (1999). Constitución y control del poder. Introducción a una teoría constitucional del control. Universidad Externado de Colombia.

BENDA, Maihofer, VOGEL, HESSE, Heyde. (2001). Manual de Derecho Constitucional. Editorial Marcial Pons.

CONSTITUCIÓN ESPAÑOLA (s. f.). Doctrinas del Tribunal Constitucional, Tribunal Supremo y Tribunal Europeo de Derechos Humanos. Tercera Edición. Colex.

CONSTITUCIÓN POLÍTICA DE COLOMBIA (2005). Bogotá-Caracas-Santiago-Lima: Legis Editores S. A.

CRUZ VILLALÓN, Pedro. (s. f.). La formación del control de constitucionalidad. Centro de Estudios Políticos y Constitucionales. Madrid.

FERRAJOLI, Luigi (2003). Pasado y futuro del Estado de Derecho. En: CARBONELL, Miguel -Compilador-. Neoconstitucionalismo(s). Editorial Trotta.

FORERO SALCEDO, José Rory. (2011-2). Fundamentos constitucionales de la potestad disciplinaria del Estado colombiano. La influencia del Derecho comparado (Primera edición). Universidad Libre de Colombia.

GARCÍA MARTÍNEZ, María Asunción. (1987). El procedimiento legislativo. Monografía 10. Publicación del Congreso de los Diputados.

GARCÍA DE ENTERRÍA, Eduardo. (s. f.). La Constitución como norma y el Tribunal Constitucional. Editorial Civitas, S. A.

JIMÉNEZ ASENSIO, Rafael. (2003). El constitucionalismo. Proceso de formación y fundamentos del Derecho constitucional (Segunda edición revisada y ampliada). Marcial Pons.

KELSEN, Hans. (2001). La garantía jurisdiccional de la Constitución (la justicia constitucional). Universidad Nacional Autónoma de México, Traducción de Ronaldo Tamayo y Salmorán. Serie de Ensayos Jurídicos nro. 5. 

jurisdiccional de la función legislativa

PERALTA, Ramón (1994). La interpretación del ordenamiento jurídico conforme a la norma fundamental del Estado. Servicio de publicaciones Facultad de Derecho, Universidad Complutense de Madrid.

PÉREZ TREMPS, Pablo (1985). Tribunal Constitucional y Poder Judicial. Centro de Estudios Constitucionales. Madrid.

RETORTILLO, Martín. El control por el Tribunal Constitucional de la actividad legislativa del Parlamento. RAP. nro. 107.

RUBIO LLORENTE y ARAGÓN REYES (1984). La jurisdicción constitucional en la Constitución española de 1978. Tecnos.

SCHMITT, Carl (1998). La defensa de la Constitución (Segunda edición). Tecnos.

VEGA GARCÍA, Pedro De (1979). Jurisdicción constitucional y crisis de la Constitución. Rep. nro. 7.

VELÁSQUEZ TURBAY, Camilo E. (2001). Derecho Constitucional (Segunda edición). Universidad Externado de Colombia. 